The Free Internet Journal

for Organic Chemistry
Review

Arkivoc 2018, part ii, 215-232

\title{
Superelectrophiles in ring-forming reactions
}

\author{
Douglas A. Klumpp* and Sean Kennedy \\ Department of Chemistry and Biochemistry, Northern Illinois University, DeKalb, IL 60178 \\ Email: dklumpp@niu.edu
}

Dedicated to Professor Kenneth Laali on the occasion of his $65^{\text {th }}$ birthday

Received 07-20-2017

Accepted 10-27-2017

Published on line 12-11-2017

\section{Abstract}

Superelectrophiles are inherently reactive species and there have been many recent applications of these intermediates in cyclization reactions. Diverse electrophilic centers have been utilized in these synthetic reactions including carboxonium, carbenium, carbonium, iminium, and other ions. This article describes these recent advances, dating from the last comprehensive review in 2007 up to June 2017.<smiles>COC(=O)C(Cc1ccc(C(C)C)cc1)C(C)=O</smiles><smiles>C=CC[NH+](CCC)Cc1ccc([N+](=O)[O-])cc1</smiles>

carbocycles and heterocycles<smiles></smiles><smiles>O=C(/C=C/C=C/c1ccccc1)c1ccccc1</smiles>

Keywords: Superelectrophile, superacid, cyclization, heterocycle 


\section{Table of Contents}

1. Introduction

2. Carboxonium Ion Superelectrophiles

3. Carbocation Superelectrophiles
3.1 Carbenium ions $-\mathrm{sp}^{3}$ centers
3.2 Carbenium ions - vinyl cations
3.3 Carbonium ions

4. Nitrogen-Based Superelectrophiles

5. Fluorinated Superelectrophiles

6. Conclusions

Acknowledgements

Abbreviations

References

\section{Introduction}

In a 1964 paper, Staskun described the influence of excess $\mathrm{H}_{2} \mathrm{SO}_{4}$ or $\mathrm{AlCl}_{3}$ on the cyclizations of $\beta$-ketoamides (the Knorr reaction). ${ }^{1}$ He suggested the enhanced yields for the Knorr reaction - in the presence of excess acid - is likely due to the multiple protonations of the dicarbonyl compound. This represented the first mention of highly ionized electrophiles in acid-promoted reactions and it was a predecessor of the superelectrophilic reactivity theory. The concept of superelectrophilic reactivity was formally developed in the 1970s by Olah and coworkers. $^{2}$ In their seminal paper, an explanation was brought forth to explain the exceptionally high electrophilic reactivities of nitronium and acetylium salts (1 and $\mathbf{4}$ ) in superacid media (Scheme 1). It was suggested that the cationic species are partially or completely protonated - leading to greater positive charge and higher electrophilic reactivities. Ions, such as 2, 3, and 5, became known as superelectrophiles. Multidentate coordination to strong Lewis acids may similarly produce superelectrophilic ions. Since this report, numerous other superelectrophilic systems have been described in the literature. ${ }^{3}$ They have been studied in both the condensed and gas phase. Many outstanding theoretical studies have likewise been reported in the literature, as the computational work explores the novel reactivities and structures of these highly charged organic ions.

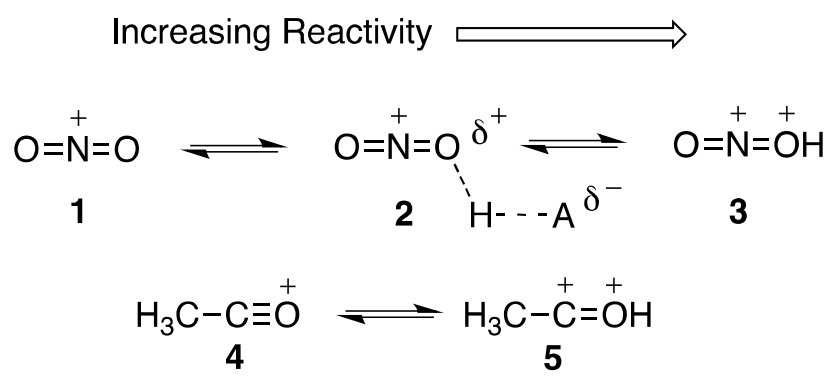

\section{Scheme 1}


Most superelectrophilic synthetic transformations use highly acidic or even superacidic reaction conditions. ${ }^{4}$ Because monocationic electrophiles are very weak bases, strong acids are usually required for further protonation of these species. Perhaps the most commonly used superacid is trifluoromethane sulfonic acid, $\mathrm{CF}_{3} \mathrm{SO}_{3} \mathrm{H}$ (triflic acid). Triflic acid has several advantages, including a very high acid strength $\left(H_{0}-14.1\right)$. It is also not HF-based, it is non-oxidizing, and it is commercially available in large quantities. Moreover, a procedure has been reported for the quantitative recycling of triflic acid. ${ }^{5}$ Occasionally, stronger superacids have been used in these synthetic methods, such as $\mathrm{HF}_{-} \mathrm{SbF}_{5}, \mathrm{CF}_{3} \mathrm{SO}_{3} \mathrm{H}-\mathrm{SbF}_{5}$, and $\mathrm{FSO}_{3} \mathrm{H}-\mathrm{SbF}_{5}$. Among the Lewis acids, the most common reagents are the aluminum halides. Several recent superelectrophilic reactions use excess $\mathrm{AlCl}_{3}$ or $\mathrm{AlBr}_{3}$ to accomplish the chemistry.

As highly reactive electrophilic species, the superelectrophiles are capable of reacting with weak nucleophiles. This includes deactivated arene nucleophiles, such as acyl-, halogen-, and nitro-substituted arenes. Numerous superelectrophilic cyclizations have also been reported involving reactions with tethered aryl groups. Several reports have even described superelectrophilic reactions with alkanes. In these cases, the superelectrophile may insert directly into a $\mathrm{C}-\mathrm{H}$ or $\mathrm{C}-\mathrm{C} \sigma$-bond. The chemistry of superelectrophiles was reviewed in 2008 by Olah and Klumpp in a monograph on this topic. ${ }^{3}$ In the following paper, superelectrophilic cyclization chemistry will be reviewed - with emphasis on studies published after 2007.

\section{Carboxonium Ion Superelectrophiles}

Carboxonium ions are well known for the high electrophilic reactivities. ${ }^{6}$ The work of Mayr and colleagues have shown ions 6 and 7 to possess electrophilicity parameters of 2.97 and 1.12 (Scheme 2). ${ }^{7}$ This level of reactivity is of similar magnitude to some benzhydryl and allylic carbocations. It has been well established that adjacent electron

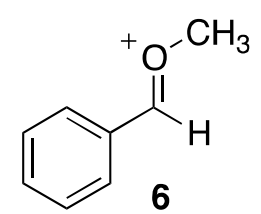

2.97

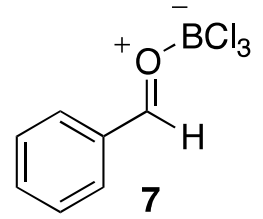

1.12

\section{Scheme 2}

withdrawing groups and cationic charge centers can greatly enhance the reactivities of carboxonium ion groups. Not surprisingly, the high reactivities of superelectrophilic carboxonium ions has proven useful in synthetic chemistry.

Among the recent cyclization strategies using carboxonium ions, Ohwada and coworkers examined the superacid-promoted cyclizations of a series $\beta$-ketoesters and related systems. ${ }^{8}$ For example, compound $\mathbf{8}$ reacts in excess triflic acid (10 equivalents) to provide the indene 9 in $88 \%$ yield as a mixture of ester and acid products (72:28 ratio). NMR studies indicate that the $\beta$-ketoesters are diprotonated at the carbonyl groups (10) at an acid strength of $H_{0}-11$. In kinetic studies, it was observed that the cyclization rate increased linearly with acid strengths above $H_{0}-11$. This was taken as evidence for further protosolvation and the involvement of a tricationic superelectrophile (i.e., 11 or 12). Theoretical calculations show a dramatic lowering of the LUMO with formation of the trication - an electronic effect that likely triggers cyclization. 
<smiles>[R]OC(=O)C1=C(C)c2cc(C(C)C)ccc2C1</smiles>

\section{Scheme 3}

There have been other reports of dicarbonyl compounds forming of superelectrophiles - often from diprotonation. A recent study demonstrated the conversion of $\alpha$-acyl $\mathrm{N}$-aryl cinnamamides to indeno[2,1c]quinolin-6(7H)-ones promoted by polyphosphoric acid (Scheme 4). ${ }^{9}$ For example, the amide (11) leads to the heterocyclic product (13) in good yield. Although the exact sequence of bond forming steps is not completely known, the chemistry is initiated by the diprotonated species 12 . In a related reaction, a novel synthesis of quinolin-2(1H)-ones has been reported in which penta-2,4-dienamides were used as precursors. ${ }^{10}$ The $\mathrm{H}_{2} \mathrm{SO}_{4}$-mediated reaction of substrate 14 provides the heterocycle $\mathbf{1 5}$ in good yield. The authors suggest a mechanism involving formation of the dicationic superelectrophile $\mathbf{1 6}$ and cyclization. An unusual styrene elimination step from $\mathbf{1 7}$ then leads to the final product (15).<smiles>CC(=O)/C(=C\c1ccccc1)C(=O)Nc1ccccc1</smiles>

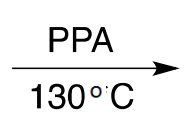<smiles>CC(=O)C(=Cc1ccccc1)C(=O)Nc1ccccc1</smiles>

12<smiles>CC1c2ccccc2-c2c1c(=O)[nH]c1ccccc21</smiles>

\section{Scheme 4}<smiles>CC(=O)C(=CC=Cc1ccccc1)C(=O)Nc1ccc(C)cc1</smiles><smiles>CC(=[OH+])/C(=C\C=C\c1ccccc1)C(=[OH+])Nc1ccccc1</smiles>

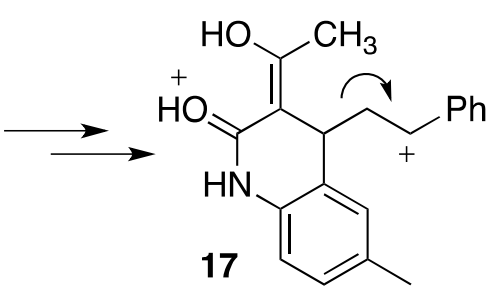<smiles>C=C(CC)c1ccccc1</smiles>

\section{Scheme 5}


It has been known for several years that protonated $N$-heterocycles may contribute to superelectrophilic systems. ${ }^{11}$ This strategy was utilized to prepare indenes by cyclodehydrations. ${ }^{12}$ For example, pyridyl ketone (18) undergoes cyclization in the presence of $\mathrm{CF}_{3} \mathrm{SO}_{3} \mathrm{H}$ to provide the pyridylsubstituted indene (19) in $76 \%$ yield (Scheme 6). The chemistry is assumed to go through the dicationic carboxonium ion (20) which leads to the indene. Similar conversions were accomplished with pyrimidine, imidazole, oxazole, thiazole, quinoline, and benzothiazole systems (70-98\% yields). A key aspect of the chemistry involves the lowering of the LUMO at the carboxonium ion by the influence of the neighboring cationic group. This is seen by comparing 1,3-diphenylpropan-1-one with pyridyl ketone (18). The two isoelectronic species $\mathbf{2 0}$ and $\mathbf{2 1}$ exhibit dramatically different electronic structures, as the dicationic species $\mathbf{2 0}$ has a calculated LUMO at $-11.96 \mathrm{eV}$ and the analogous monocation (21) has a LUMO at -9.74 eV. While 1,3diphenylpropan-1-one does undergo cyclodehydration to form 1-phenylindene, the chemistry requires forcing conditions. $^{13}$
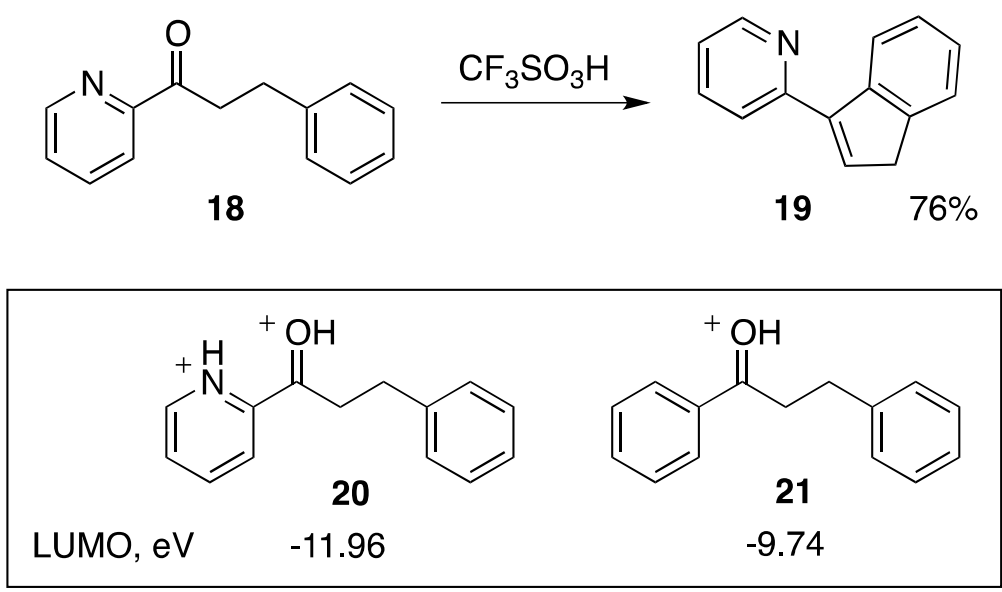

\section{Scheme 6}

In a related cyclodehydration, a series of imidazo[1,2-a]pyridines were prepared from heterocyclic ketones. ${ }^{14}$ Compound 22 provides the condensed arene $\mathbf{2 4}$ in 85\% from cyclization in triflic acid (Scheme 7). The superelectrophilic carboxonium ion $\mathbf{2 3}$ is a key reactive intermediate, as its formation triggers formation of the new C-C bond. Further dehydration steps give product 24.

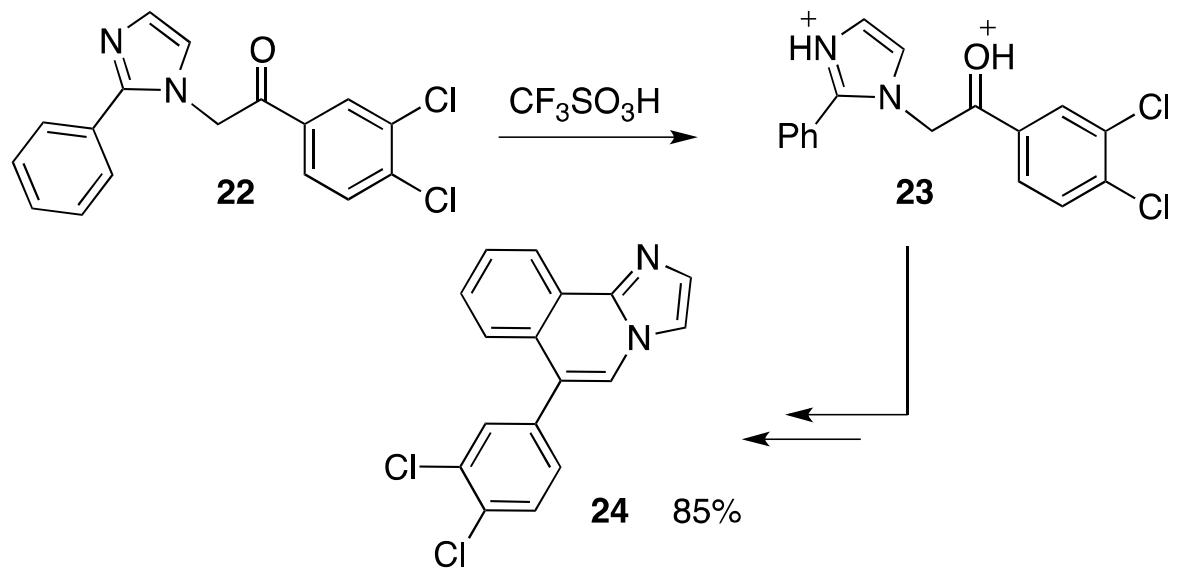

\section{Scheme 7}


Cyclizations of phenethyl-substituted pyridinecarboxaldehydes provide a useful route to benzocycloheptapyridines. ${ }^{15}$ For example, compound 25 reacts in superacid with an arene nucleophile to provide the cyclization product $\mathbf{2 6}$ (Scheme 8). Two superelectrophiles are involved in the transformation - a pyridinium-carboxonium dication (28) and a pyridinium-carbenium dication (29). Likewise, the chemistry may be used to prepare the 10,11-dihydro-5H-benzo[4,5]cyclohepta[1,2-b]pyridin-5-ones (i.e., 27), by hydrolytic work-up of the cyclization product and subsequent oxidation. The benzocycloheptapyridines and related structures are useful building blocks in drug synthesis.
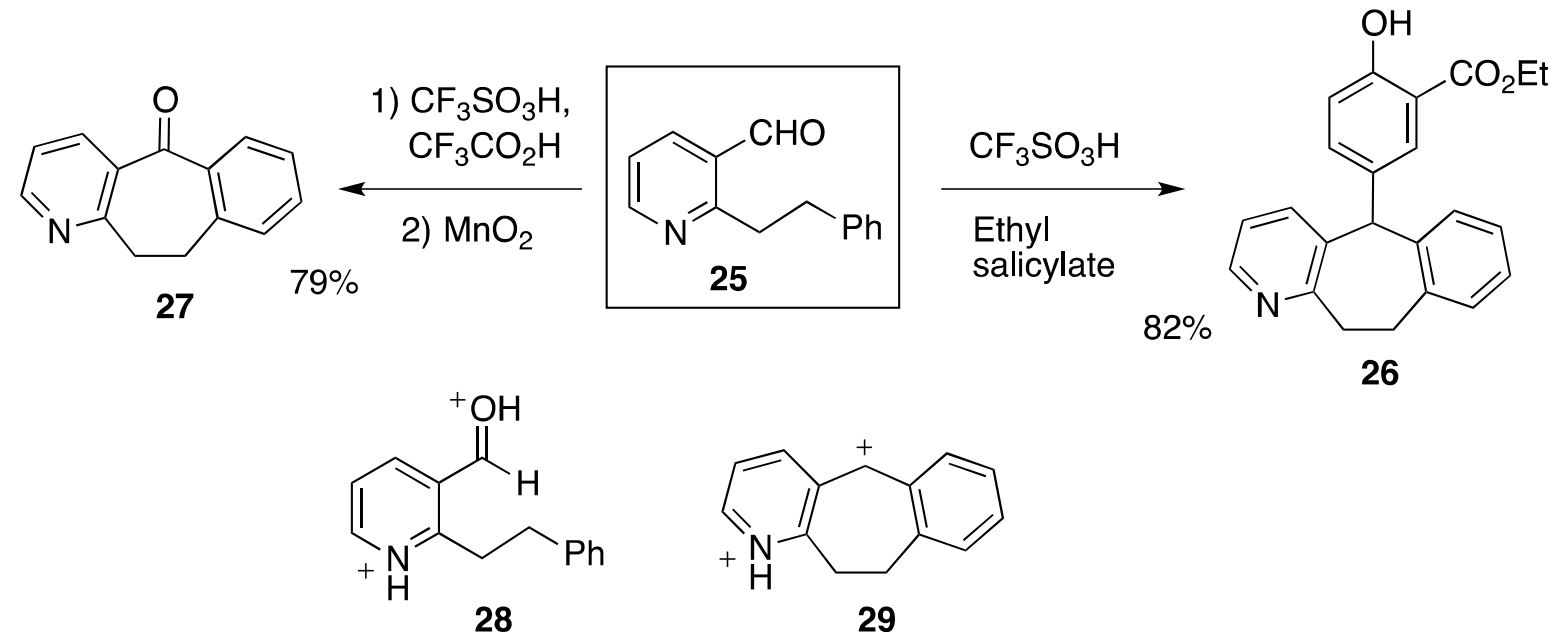

\section{Scheme 8}

The fluorene ring system has been generated by cyclization reactions involving heterocyclic ketones. ${ }^{16}$ For example, the pyrazine derivative $\mathbf{3 0}$ undergoes reaction in superacid with benzene to give the 9,9diarylfluorene product 34 in $91 \%$ yield (Scheme 9). The cyclization step is thought to involve the tricationic carboxonium (31) as the intermediate leading to the new carbocycle. Dehydration through the oxonium ion 32 leads to the highly electrophilic fluorenyl ion 33. This tricationic species has been directly observed by low temperature NMR using stable ion conditions. ${ }^{17}$ Reaction with benzene gives $\mathbf{3 4}$ as the final product. The condensation chemistry was also adapted to a polymer synthesis wherein the fluorene ring system is part of the polymer backbone.<smiles>O=C(c1cnccn1)c1ccccc1-c1ccccc1</smiles>

30<smiles>CC1CC1c1c[nH+]cc[nH+]1</smiles>

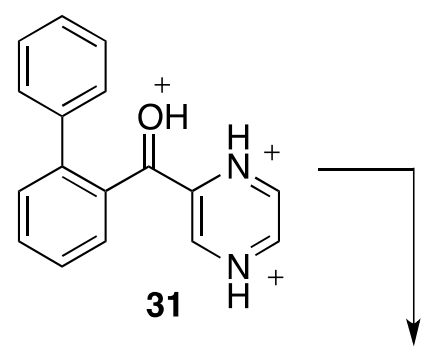

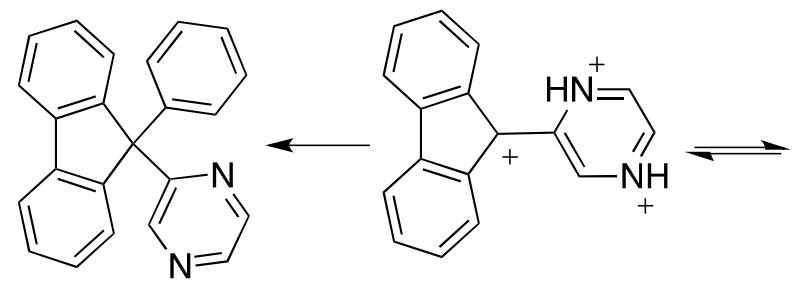

$3491 \%$
33

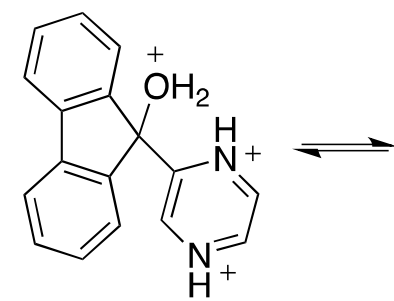

32<smiles>OC1(c2c[nH+]cc[nH+]2)c2ccccc2-c2ccccc21</smiles>

Scheme 9 
Aryl-substituted oxindoles are known for their biological activities and several synthetic approaches have utilized superelectrophiles. One such method involves cyclizations of $\alpha$-ketoamides (Scheme 10). ${ }^{18}$ For example, substrate $\mathbf{3 5}$ condenses in the presence of superacid and an arene nucleophile. A mechanism is proposed involving protonation of both carbonyl groups - forming superelectrophile $\mathbf{3 7 a}$ or $\mathbf{3 7 b}$ - followed by cyclization. A second dicationic intermediate (38) reacts with the arene to provide the final condensation product 39.<smiles>O=C(Nc1ccccc1)C(=O)Nc1ccccc1</smiles>

or<smiles>O=C1Nc2ccccc2C1(c1ccccc1)c1ccccc1</smiles>

39

$94 \%$

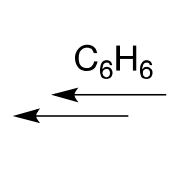

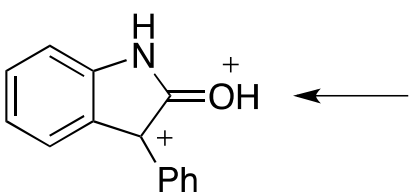

38<smiles>[OH+]=C1Nc2ccccc2C1([OH2+])c1ccccc1</smiles><smiles>O=C(Nc1ccccc1)C(=[O+])c1ccccc1</smiles>

$37 b$

\section{Scheme 10}

\subsection{Carbocation superelectrophiles: carbenium ions $-\mathrm{sp}^{3}$ centers}

A series of unusual ring-fused heterocycles were prepared by ionization of triaryl alcohols. ${ }^{19}$ For example, substrate $\mathbf{4 0}$ gives compound $\mathbf{4 1}$ in excellent yield. These reactions are thought to involve an equilibrium between tri- and dicationic species (i.e., $\mathbf{4 2}$ and 43). Theoretical calculations revealed that direct cyclization of the trication is unlikely, but rather that deprotonation occurs to give the dication and subsequent $\mathrm{C}-\mathrm{N}$ bond formation leads to the new ring. While it may seem counterintuitive - forming an unprotonated benzimidazole ring in superacid - it is suggested that the high charge density of ion $\mathbf{4 2}$ leads to increased $\mathrm{N}-\mathrm{H}$ acidity.

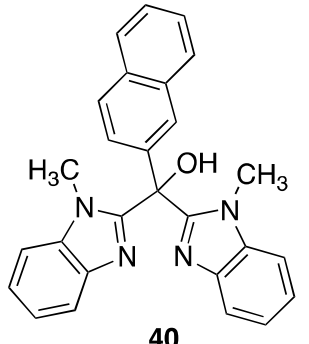

40

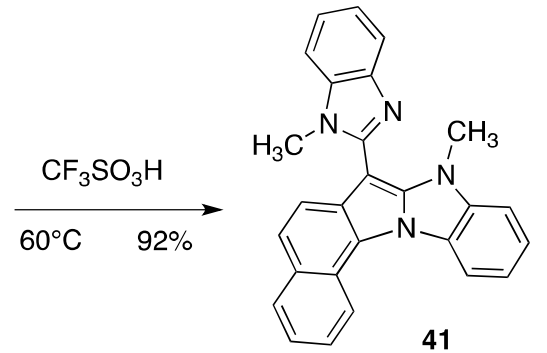

41

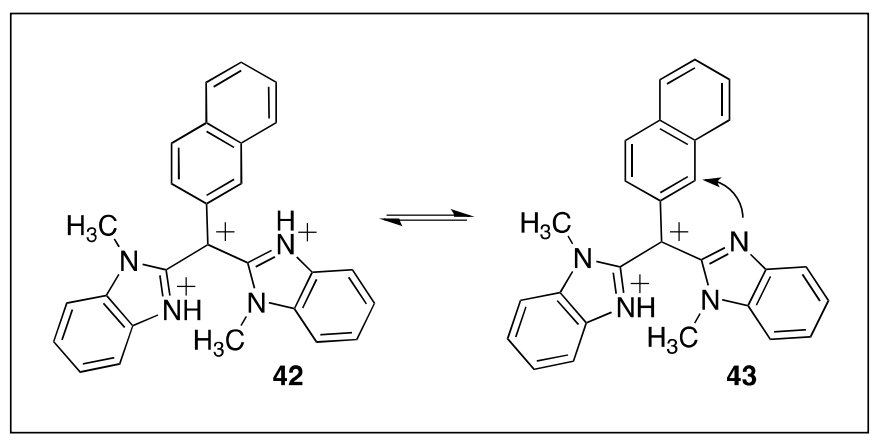

\section{Scheme 11}

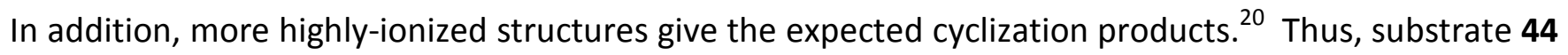
gives the pyrido[1,2-a]indole $\mathbf{4 7}$ in $85 \%$ yield from a reaction in superacid (Scheme 12). This transformation 
involves an equilibrium between the tetracationic species (45, observable by NMR) and the tricationic species 47. As above, the highly-charged tetracationic structure facilitates $N$-deprotonation - despite being in the presence of a superacid - and the trication $\mathbf{4 6}$ is formed. This leads to the cyclization. Theoretical calculations

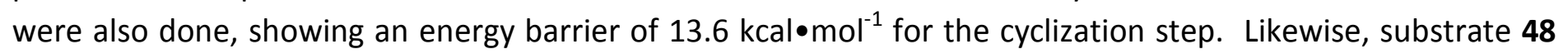
leads to the functionalized pyrido[1,2-a]indole 49 in $90 \%$. It is assumed that the cyclization occurs via a tetracationic superelectrophilic intermediate.

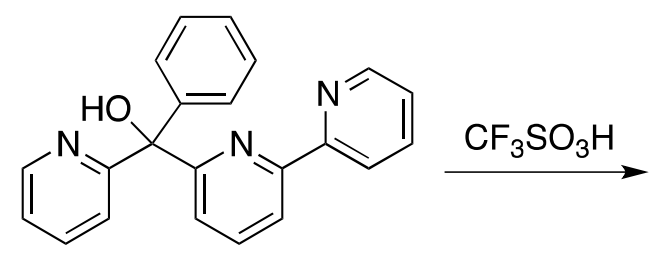

44<smiles>c1ccc(-c2c3ccccc3n3c(-c4ccccn4)cccc23)nc1</smiles>

$47 \quad 85 \%$<smiles>OC(c1ccccc1)(c1cccc(-c2ccccn2)n1)c1cccc(-c2ccccn2)n1</smiles>

48<smiles>c1ccc([C@@H](c2cccc(-c3cccc[nH+]3)n2)c2cccc[nH+]2)cc1</smiles>

45<smiles>c1ccc([C@H](c2cccc(-c3cccc[nH+]3)n2)c2cccc[nH+]2)cc1</smiles>

46

\section{Scheme 12}

Diazafluorenones are the starting point for an interesting group of superelectrophiles leading to spirocyclic products. ${ }^{21}$ Compound $\mathbf{5 0}$ reacts in superacid with, for example, 1-naphthol to give the spirocyclic product $\mathbf{5 1}$ in $45 \%$ yield (Scheme 13). The conversion likely involves tricationic species, such as superelectrophile $\mathbf{5 2}$.

A route to functionalized aza-polycyclic aromatic compounds has been described and the chemistry utilizes superelectrophilic carbocations. ${ }^{22}$ The ring closing and opening cascade involves ionization of substrates such as alcohol $\mathbf{5 3}$ to give dication $\mathbf{5 4}$. This species undergoes cyclization to initially provide structure 55. Ring opening - by protonated at the ipso position of the aryl group - leads to the final product 56. Aromatization of the new ring likely drives the equilibrium towards product 56. 
<smiles>O=C1c2cccnc2-c2ncccc21</smiles><smiles></smiles>

\section{Scheme 13}

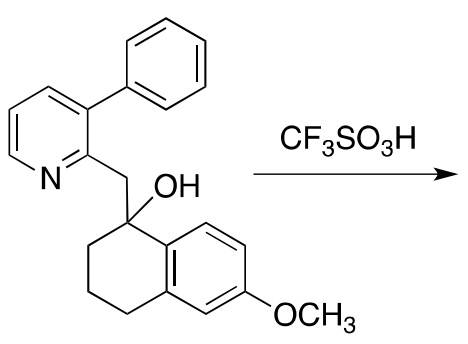

53<smiles>COc1ccc2c(c1)CCC[C]2Cc1[nH+]cccc1-c1ccccc1</smiles>

54

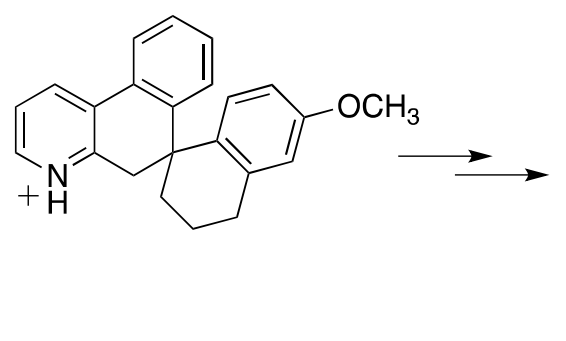

55<smiles>COc1cccc(CCCc2cc3ncccc3c3ccccc23)c1</smiles>

$5696 \%$

\section{Scheme 14}

Carbocation cyclization involving olefinic bonds is well-known in synthetic chemistry and biochemistry. Some examples are also known among superelectrophilic cyclizations. For example, a recent study examined the chemistry $\mathrm{N}$-dienes and their reactions in superacid. ${ }^{23}$ Among the report transformations, diene $\mathbf{5 7}$ provides the piperidine derivative 61 in 55\% from HF-SbF 5 (Scheme 15). The chemistry is thought to involve formation of several superelectrophiles. First, the 1,3-dication (58) is formed and this lead to an initial cyclization intermediate, dication 59. Charge separation is a powerful driving force in the chemistry of superelectrophiles, and as such, the 1,3-dication 59 isomerizes to the 1,4-dication $\mathbf{6 0}$. Fluoride attack at the carbocation site then leads to the final product (61). 
<smiles>C=CCN(CC=C)Cc1ccc([N+](=O)[O-])cc1</smiles>
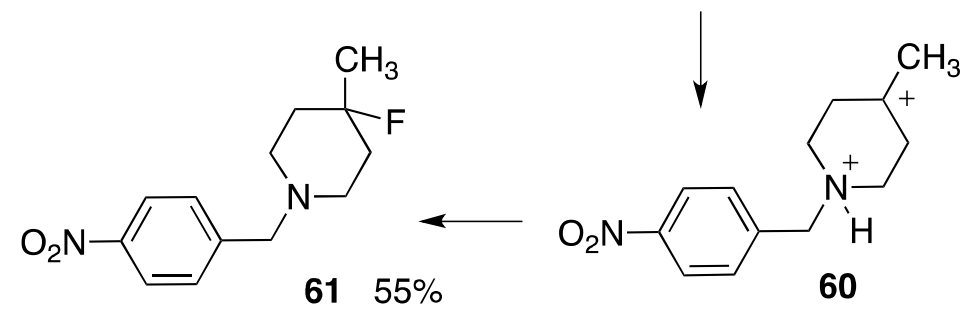

\section{Scheme 15}

\subsection{Carbocation superelectrophiles: vinyl cations}

The study of vinyl cations began in the 1960s and it soon became apparent that - like aliphatic carbocations the vinyl cations were reactive electrophilic species. ${ }^{24}$ The first vinyl cations having dicationic character were generated from aminoalkynes in acid-catalyzed reactions leading to heterocycles. ${ }^{25,26}$ Although the original reports did not identify the intermediates as dications, protonation of the aminoalkynes in strong acid almost certainly gave the superelectrophilic vinyl cations. More recently, superectrophilic vinyl cations have been used in several ring-forming synthetic reactions. Some of this chemistry is described in a recent review of protonation of acetylenic compounds. ${ }^{27}$

Vasilyev and coworkes have examined a variety of superelectrophilic vinyl cations, using experimental and theoretical methods. For example, a synthetic route leading to 3,4-dihydroquinolin-2(1H)-ones was reported. ${ }^{28}$ The chemistry utilizes aryl-substituted propiolamides in triflic acid-promoted reactions. Amide 62 gives the heterocycle $\mathbf{6 3}$ in good yield and a mechanism is proposed involving two superelectrophilic intermediates - a carboxonium-vinyl dication (64) and the carboxonium-carbenium dication (65).

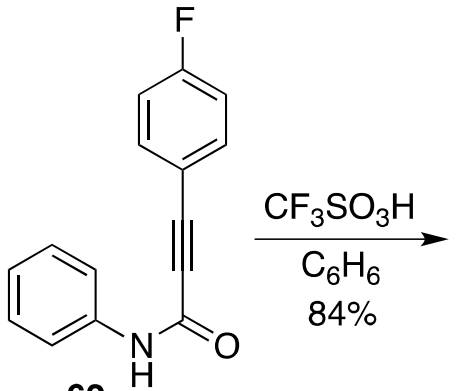

62<smiles></smiles>

63<smiles>O=C(CC(Br)Br)Nc1ccccc1</smiles>

\section{Scheme 16}

Other derivatives of 3-phenylpropiolic acid were also subjected to reactions in excess triflic acid or aluminum halides. ${ }^{29}$ In general, two types of products were obtained - 4,4-diaryl-3,4-dihydroquinolin-2-one 
(i.e., 63) and 4-phenylquinolin-2(1H)-one. Similar products were obtained from the ester and thioester derivatives.

A method for preparing functionalized indenes has been developed using enynones as the starting

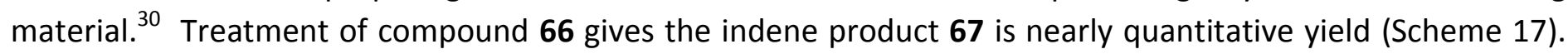
A key step involves formation of the superelectrophile 68, which reacts with benzene. The resulting intermediate then undergoes cyclization to the indene 67 via the carboxonium ion (69) or a more highly protonated species.
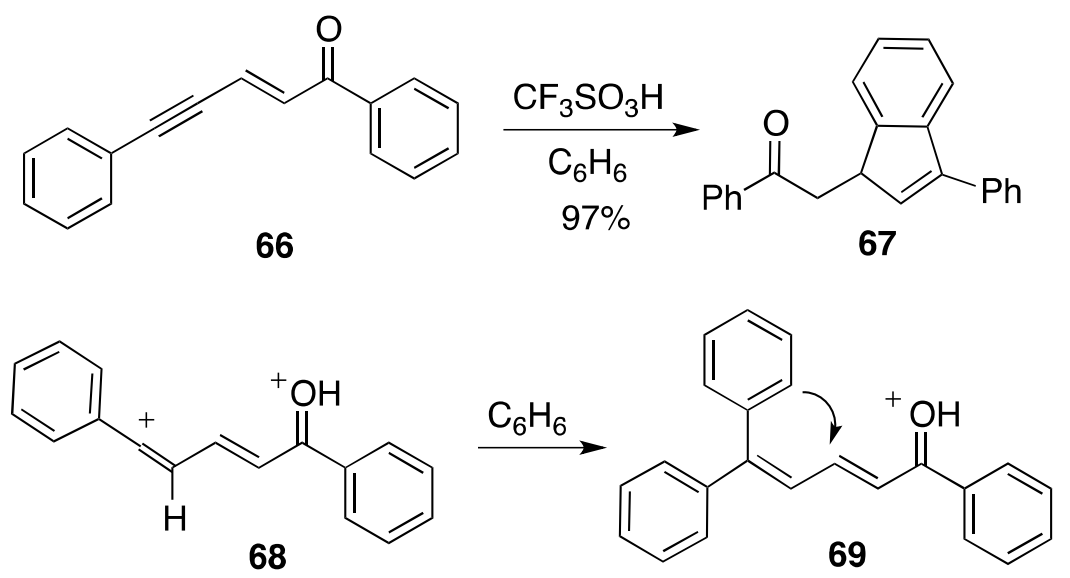

\section{Scheme 17}

\subsection{Carbocation superelectrophiles: carbonium ions}

According to the nomenclature proposed by Olah, trivalent carbocations (i.e., $\mathrm{CH}_{3}+$ ) are described as carbenium ions and higher coordinate carbocations (i.e., $\mathrm{CH}_{5}+$ ) are described as carbonium ions. ${ }^{31}$ Both types of cationic centers are known in superelectrophilic systems. ${ }^{3}$ Carbonium ions are generally characterized by 3 center-2 electron bonding. While numerous di- and tricationic carbonium ions have been studied computationally, fewer superelectrophilic carbonium ions have been generated in the condensed phase.

The first example of a superelectrophilic carbonium ion cyclization was reported recently by Thibaudeau and coworkers. ${ }^{32}$ This remarkable cyclization involves anti-Markovnikov additions to $N$-allylic derivatives. One such conversion produced the tetrahydroquinoline product $\mathbf{7 1}$ from the nitroaniline derivative $\mathbf{7 0}$ (Scheme 18). On the basis of theoretical calculations, a mechanism has been proposed wherein a tricationic species is formed that includes a symmetrical hydrido-bridged, carbonium structure (from protonation of the olefin). Cyclization at the protonated olefin then provides the tetrahydroquinoline product. The chemistry is particularly striking when considering the deactivating effects of the nitro group on arenes and aryl groups.<smiles>C=CCNc1ccc([N+](=O)[O-])cc1C</smiles><smiles>Cc1cc([N+](=O)[O-])ccc1NCC1CC1</smiles>

\section{Scheme 18}




\section{Nitrogen-Based Superelectrophiles}

A variety of nitrogen-based superelectrophiles are known. As described in the introduction, the protionitronium ion $\left(3, \mathrm{NO}_{2} \mathrm{H}^{2+}\right)$ was one of the first ions to be recognized for its superelectrophilic reactivity. Several studies have also shown protonated nitro groups to be useful components of superelectrophilic systems. Other nitrogen-based groups have been demonstrated to be useful in superelectrophilic chemistry, including nitrilium ions, iminium ions, and ammonium ions. This includes cyclization chemistry.

In one such study, the superacid-catalyzed cyclizations of arylcyanopropionates was examined. ${ }^{33}$ Reaction of nitrile $\mathbf{7 3}$ provides the dihydronathalene derivative $\mathbf{7 5}$ in good yield. A mechanism is proposed involving the distonic superelectrophile $\mathbf{7 4}$ as the key reactive intermediate leading to cyclization. NMR studies of a model cyanopropionate in superacid provide further evidence for the nitrilium-carboxonium dication intermediates.

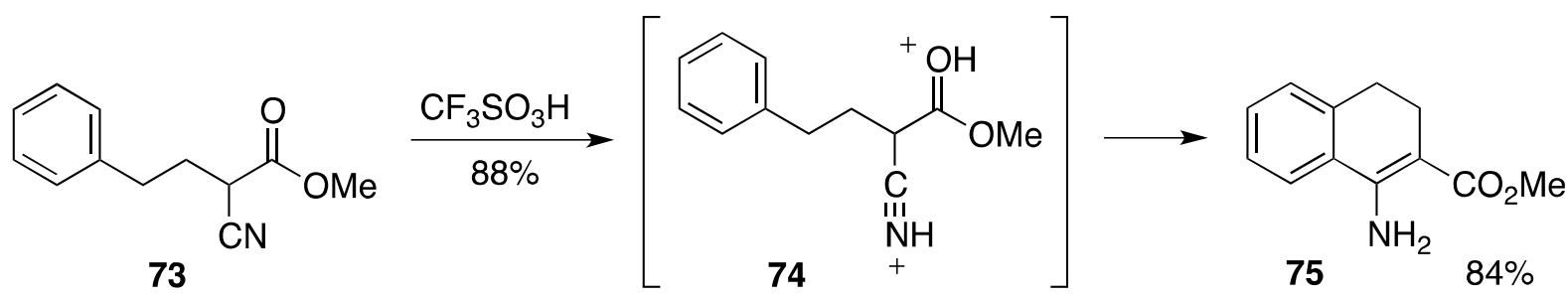

\section{Scheme 19}

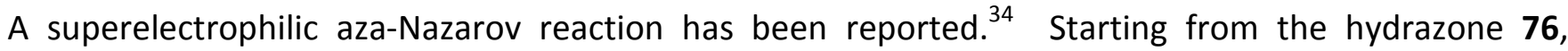
treatment with excess (7 equivalents) of triflic acid and acetic anhydride leads to the pyrrole 77 (Scheme 20). A mechanism is proposed involving the superelectrophile 79, where the carbonyl oxygen and hydrazone nitrogen are protonated. Computational studies showed that an aza-Nazarov cyclization involving the

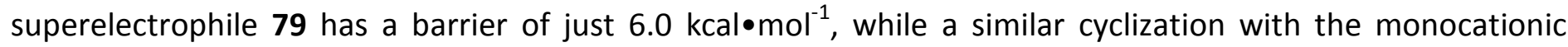
intermediate has a transition state located $13.1 \mathrm{kcal} \bullet \mathrm{mol}^{-1}$ above ion 78.
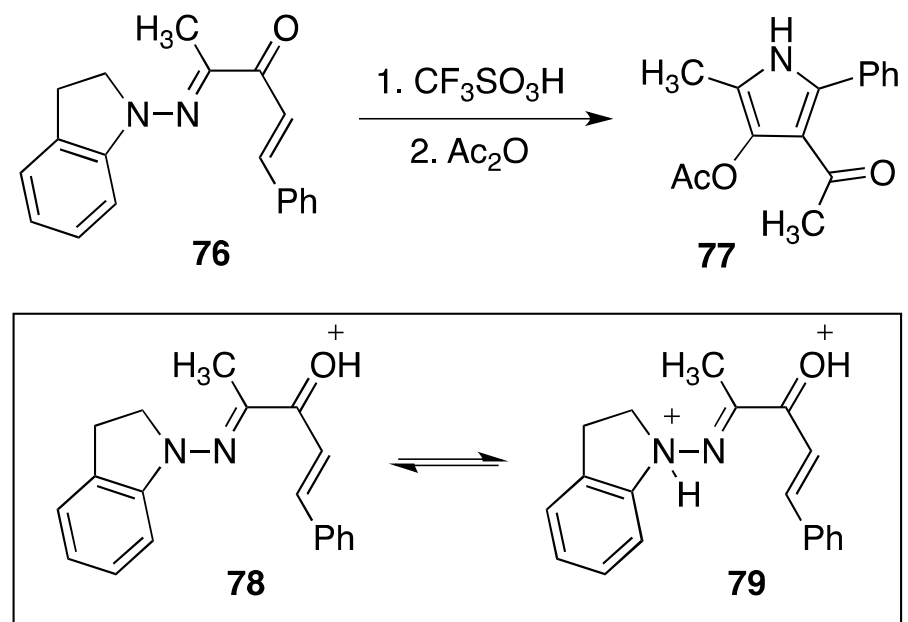

\section{Scheme 20}

Another aza-Nazarov cyclization has been reported which utilizes amido-acetal substrates. ${ }^{35}$ For example, compound $\mathbf{8 0}$ reacts in superacid to gives the ring-fused isoindolinone (81). The conversion involves 
formation of the $\mathrm{N}$-acyliminium ion (82). Though direct cyclization of the monocationic species 82 cannot be ruled out, computational studies indicate that carbonyl protonation (partial or complete) lowers the energy of cyclization. It is suggested that formation of the dication $\mathbf{8 3}$ enhances the delocalization of $\pi$-electrons facilitating the $4 \pi$-electron electrocyclization.<smiles>CCCC(CCCNC(=O)c1cc(OC)c(OC)c(OC)c1)OCC</smiles>

80

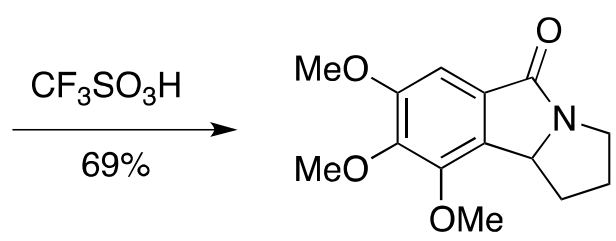

81

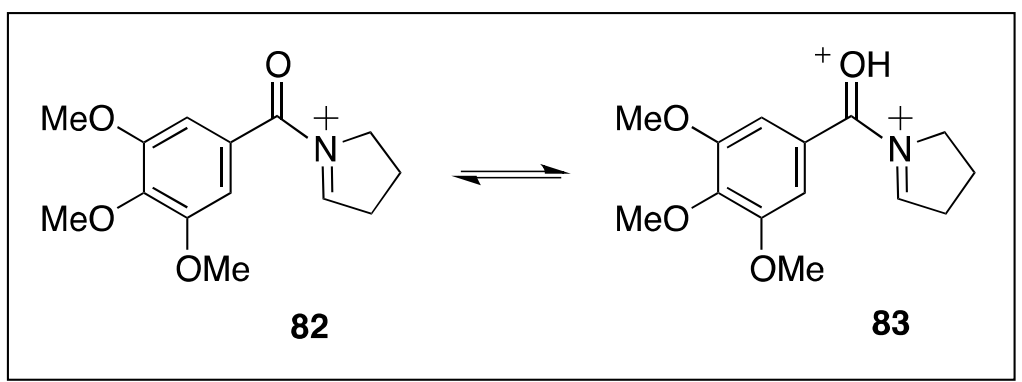

\section{Scheme 21}

A superelectrophilic system has been reported which provides 3,4-dihydroisoquinolin-1(2H)-ones and related products from aryl-substituted ureas. ${ }^{36}$ Despite the exceptional stability of the urea functional group, the 2-nitrophenyl substituent activates the urea in superacidic media. Thus, reaction of compound $\mathbf{8 4}$ in triflic acid provides the hetrocycle $\mathbf{8 5}$ in good yield. The chemistry is thought to involve protonation of the nitro and urea groups, giving the dicationic species $\mathbf{8 6}$ and $\mathbf{8 7}$ (in excess triflic acid, the pyridyl group is also protonated). DFT calculations suggest that the preferred reaction path leads to an equilibrium between 86 and 87 (structure 87 is calculated to be $11 \mathrm{kcal}^{\circ} \mathrm{mol}^{-1}$ less stable; $\mathrm{R}=\mathrm{Ph}$ ) and cleavage of 87 to a protonated isocyanate. Cyclization then occurs by a Friedel-Crafts type reaction between the neighboring phenyl group and the protonated isocyanate.
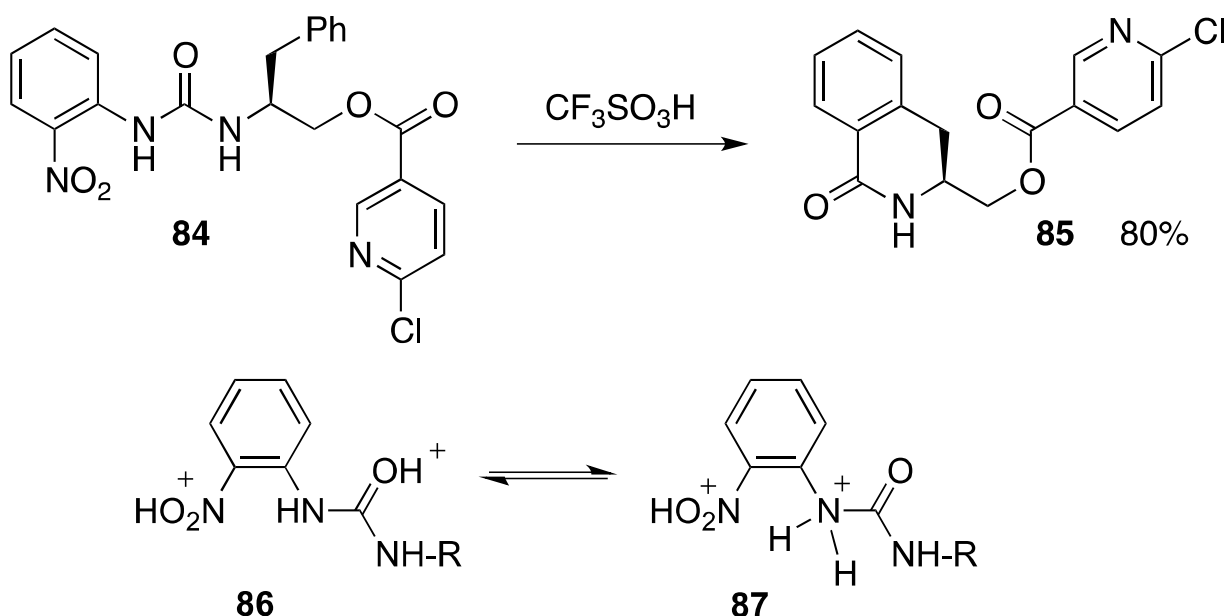

Scheme 22 
In a similar respect, intramolecular Freidel-Crafts acylation has been accomplished using an amide. ${ }^{37}$ Thus, substrate $\mathbf{8 8}$ is reacted with superacid to give the indanone product (89). Amides have typically not been useful as reagents in Freidel-Crafts reactions, however compound $\mathbf{8 8}$ is doubly protonated in superacid. This leads to cleavage to the acylium cation via transition state 90 . DFT calculations were done on a model system, indicating that $N$ - protonation at the amide leads to an intermediate with a low barrier to acylium ion cleavage $\left(+2.3 \mathrm{kcal} \cdot \mathrm{mol}^{-1}\right)$.<smiles>O=C(CCc1ccc(Br)cc1)Nc1ccc([N+](=O)[O-])cc1</smiles>

88

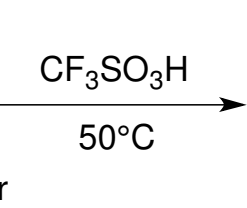

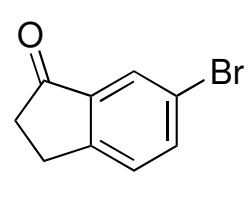

$8988 \%$

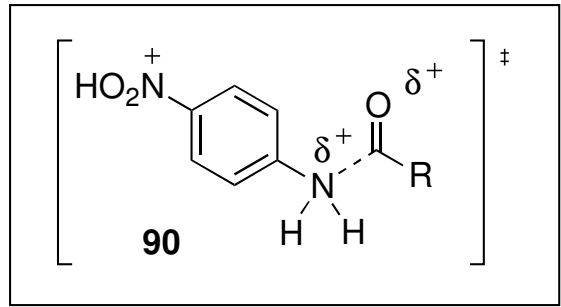

\section{Scheme 23}

\section{Fluorinated Superelectrophiles}

Because of the useful properties of fluorine-substituted organic compounds, there has been an ever intensifying need for new synthetic methods leading to these products. Fluorine substitution by itself is known to enhance the reactivities of electrophiles. Nevertheless, fluorine atoms and the $-\mathrm{CF}_{3}$ groups have also been present on several types of superelectrophiles. For example, Vasilyev and coworkers utilized trifluoromethyl-substituted enones and demonstrated them to be useful building blocks leading to functionalized indanes. ${ }^{38}$ Thus, compound 91 reacts in $\mathrm{FSO}_{3} \mathrm{H}$ and benzene at low temperature to give the hydroarylation product 92 in 68\% yield. Treatment of this intermediate with triflic acid and benzene provides the indane $\mathbf{9 3}$ in $\mathbf{7 6 \%}$ yield. The initial transformation is thought to involve superelectrophile $\mathbf{9 5}$. Some of the obtained products exhibited biological activities as cannabinoid receptor ligands.

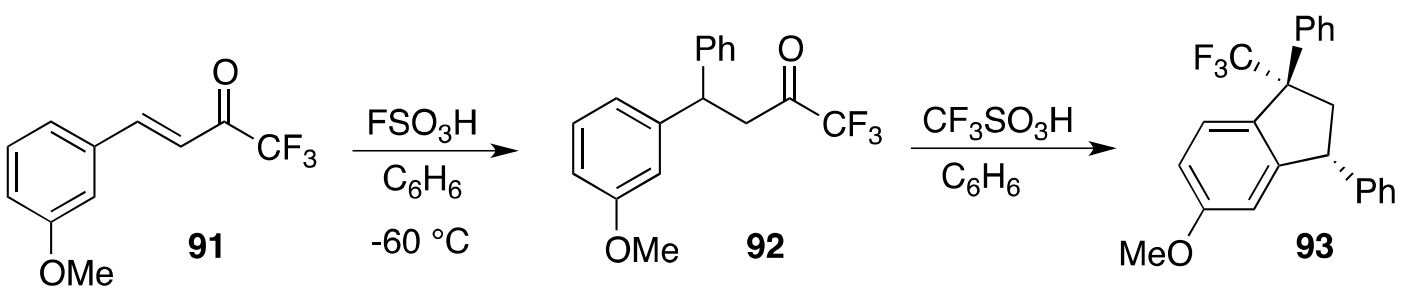<smiles>COc1cccc(C=CC(=O)C(=O)C(=O)C(F)(F)F)c1</smiles>

\section{Scheme 24}

Trifluoromethyl-substituted acrylic acids provides thiochrom-4-ones (from thiophenols) in good yields from triflic acid. ${ }^{39}$ This chemistry was likewise useful in preparing trifluoromethyl-substituted indanones and dihydrocoumarins (Scheme 25). ${ }^{40}$ Trifluoromethyl-substituted superelectrophiles, such as 96 , are proposed in 
these transformations. In a related transformation, crotonic and methacrylic acids were shown to give thiochrom-4-ones from thiophenols in a superacid promoted transformation. ${ }^{41}$ The proposed mechanism also invokes a superelectrophile arising from double protonation of the $\alpha, \beta$-unsaturated carboxylic acids.

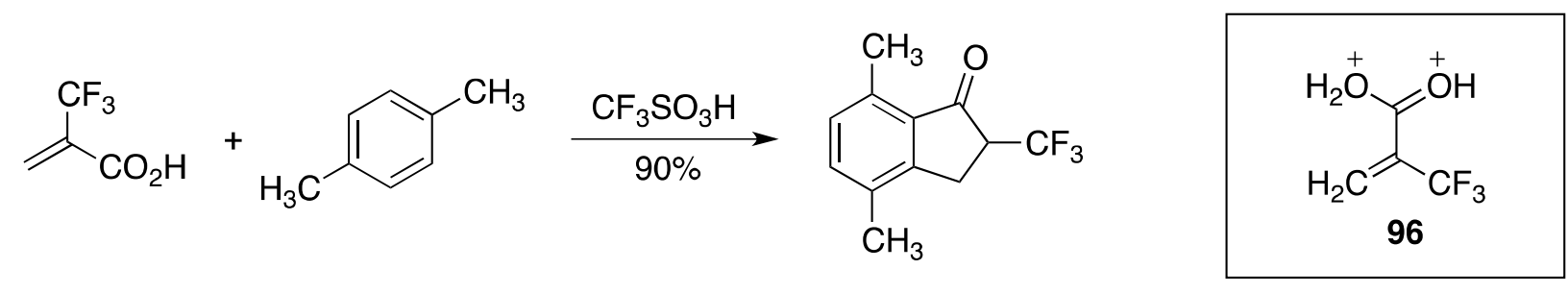

\section{Scheme 25}

A set of fluorinated quinolin-2-ones have been prepared from cinnamamides utilizing excess $\mathrm{AlCl}_{3}$ (Scheme 26). ${ }^{42}$ For example, compound $\mathbf{9 8}$ is prepared in about $50 \%$ yield from the precursor cinnamamide (97). The chemistry is thought to involve superelectrophile $\mathbf{9 9}$, wherein $X$ is a coordinating proton (formed by adventitious water) or Lewis acid. The reactivity of this electrophile is apparent by its attack on a tetrafluorophenyl group - a very weak nucleophile. A final step involving elimination of benzene provides the quinolin-2-one 98.<smiles>O=C(/C=C/c1ccccc1)Nc1cc(F)c(F)c(F)c1F</smiles>

97

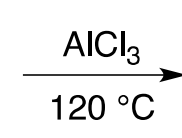<smiles>O=c1ccc2c(F)c(F)c(F)c(F)c2[nH]1</smiles>

98

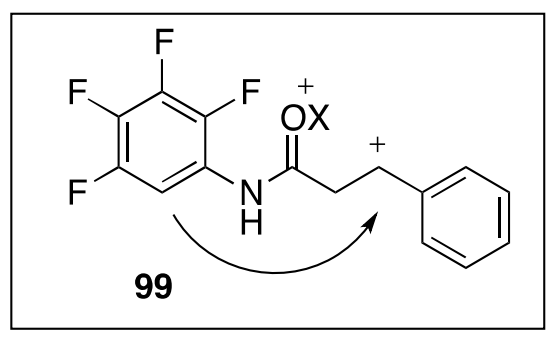

\section{Scheme 26}

\section{Conclusions}

Superelectrophiles are known to exhibit novel reactivities - often reacting with relatively inert reagents and functional groups. Moreover, a diverse set of functional groups can lead to superelectrophilic structures. Consquently, superelectrophilic chemistry is useful in the synthesis of various carbocyclic and heterocyclic structures. In the 50 years since Staskun suggested dicationic intermediates in the Knorr cyclization, there has been great progress in the use of superelectrophiles in cyclization reactions. Almost certainly, the next 50 years will see many more exciting advances in this chemistry.

\section{Acknowledgements}

In providing resources for the study of superelectrophilic chemistry, the National Science Foundation (grant nos. 1300878 and 0749907) and National Institutes of Health - NIGMS (GM085736-01A1) are gratefully acknowledged. 


\section{References}

1. Staskun, B. J. Org. Chem. 1964, 29, 1153.

https://doi.org/10.2174/157017941205150821130712

2. Olah, G. A.; Germain, A.; Lin, H. C.; Forsyth, D. A. J. Am. Chem. Soc. 1975, 97, 2928.

https://doi.org/10.1016/i.tetlet.2015.10.081

3. Olah, G. A.; Klumpp, D. A. Superelectrophiles and Their Chemistry; Wiley: New York, 2008; pp 1-301.

4. Olah, G. A.; Prakash, G. K. S.; Molnar, A.; Sommer, J. M. Superacid Chemistry, $2^{\text {nd }}$ Ed. Wiley: New York, 2009; pp 1-850.

https://doi.org/10.1002/9780470421604

5. Booth, B. L.; El-Fekky, T. A. J. Chem. Soc., Perkin I 1979, 2441.

https://doi.org/10.2174/2213346101999140109142834

6. Olah, G. A.; Laali, K. K.; Wang, Q.; Prakash, G. K. S. Onium Ions; Wiley \& Sons: New York, 1998; pp 270298.

https://doi.org/10.2174/157017941006140206102255

7. Mayr, H.; Gorath, G. J. Am. Chem. Soc. 1995, 117, 7862.

https://doi.org/10.1021/ja00135a002

8. Kuouchi, H.; Sugimoto, H.; Otani, Y.; Ohwada, T. J. Am. Chem. Soc. 2010, 132, 807.

https://doi.org/10.1021/ja908749u

9. Liu, X.; Zhang, Q.; Zhang, D.; Xin, X.; Zhang, R.; Zhou, F.; Dong, D. Org. Lett. 2013, 15, 776. https://doi.org/10.1021/ol303423f

10. Liu, X.; Xin, X.; Xiang, D.; Zhang, R.; Kumar, S.; Zhou, F.; Dong, D. Org. Biomol. Chem. 2012, 10, 5643. https://doi.org/10.1039/c2ob25767j

11. Klumpp, D. A.; Lau, S. J. Org. Chem. 1999, 64, 7309.

https://doi.org/10.1021/jo9824908

12. Boblak, K. N.; Klumpp, D. A. J. Org. Chem. 2014, 79, 5852.

https://doi.org/10.1021/j05007416

13. Saito, S.; Sato, Y.; Ohwada, T.; Shudo, K. J. Am. Chem. Soc. 1994, 116, 2312.

https://doi.org/10.1021/ja00085a010

14. Kethe, A.; Naredla, R. R.; Klumpp, D. A. Helv. Chim. Acta 2013, 96, 1457.

https://doi.org/10.1002/hlca.201200590

15. Naredla, R. R.; Klumpp, D. A. Tetrahedron 2013, 69, 2137.

https://doi.org/10.1016/j.tet.2013.01.004

16. Gasonoo, M.; Sumita, A.; Giuffre, K.; Boblak, K.; Ohwada, T.; Klumpp, D. A., J. Org. Chem. 2017, 82, 6044. https://doi.org/10.1021/acs.joc.7b00311

17. Sumita, A.; Ohwada, T.; Boblak, K.; Gasonoo, M.; Klumpp, D. A., Chem. Eur. J. 2017, 23, 2566. https://doi.org/10.1002/chem.201606036

18. Sai, K. K. S.; Esteves, P. M.; Tanoue da Penha, E. T.; Klumpp, D. A. J. Org. Chem. 2008, 73, 6506. https://doi.org/10.1021/jo801208m

19. Naredla, R. R.; Zheng, C.; Nilsson Lill, S. O.; Klumpp, D. A. J. Am. Chem. Soc. 2011, 133, 13169. https://doi.org/10.1021/ja2046364

20. Gasonoo, M.; Naredla, R., R.; Nilsson Lill, S. O.; Klumpp, D. A., J. Org. Chem. 2016, 81, 11758. https://doi.org/10.1021/acs.joc.6b02220

21. Lin, D.; Wei, Y.; Ou, C.; Huang, H.; Xie, L.; Tang, L.; Huang, W. Org. Lett. 2016, 18, 6220. 
https://doi.org/10.1021/acs.orglett.6b02595

22. Kethe, A.; Li, A.; Klumpp, D. A. Tetrahedron 2012, 68, 3357.

https://doi.org/10.1016/i.tet.2012.02.047

23. Verdelle, E.; Martin-Mingot, A.; Jouannetaud, M.-P.; Bachmann, C.; Marrot, J.; Thibaudeau, S. J. Org. Chem. 2009, 74, 6025.

https://doi.org/10.1021/jo900881f

24. Dicoordinated Carbocations, Rappoport, Z.; Stang, P. J., Eds.; Wiley \& Sons: New York, 1997; pp 1-466.

25. Brooks, J. R.; Harcourt, D. N.; Waigh, R. D. J. Chem. Soc. Perkin Trans. I 1973, 2588.

https://doi.org/10.1039/p19730002588

26. Takayama, H.; Suzuki, T.; Nomoto, T. Chem. Lett. 1978, 865.

https://doi.org/10.1246/cl.1978.865

27. Vasilyev, A. V. Russ. Chem. Rev. 2013, 82, 187. https://doi.org/10.1070/RC2013v082n03ABEH004345

28. Gurskaya, L. Y.; Belyanskaya, D. S.; Ryabukhin, D. S.; Nilov, D. I.; Boyarskaya, I. A.; Vasilyev, A. V. Beilstein J. Org. Chem. 2016, 12, 950.

https://doi.org/10.3762/bjoc.12.93

29. Ryabukhin, D. S.; Gurskaya, L. Y.; Fulin, G. K.; Vasilyev, A. V. Tetrahedron 2014, 70, 6428. https://doi.org/10.1016/i.tet.2014.07.028

30. Saulnier, S.; Golovanov, A. A.; Vasilyev, A. V. RSC Adv. 2016, 6, 103546. https://doi.org/10.1039/C6RA21965A

31. Olah, G. A. J. Am. Chem. Soc. 1972, 94, 808. https://doi.org/10.1021/ja00758a020

32. Compain, G.; Martin-Mingot, A.; Frapper, G.; Bachmann, C.; Jouannetaud, M.-P.; Thibaudeau, S. Chem. Commun. 2012, 48, 5877.

https://doi.org/10.1039/c2cc32246c

33. Nakamura, S.; Sugimoto, H.; Ohwada, T. J. Org. Chem. 2008, 73, 4219. https://doi.org/10.1021/jo800674h

34. Narayan, R.; Daniliuc, C.-G.; Würthwein, E.-U. Eur. J. Org. Chem. 2012, 6021. https://doi.org/10.1002/ejoc.201200913

35. Sai, K. K. S.; O'Connor, M. J.; Klumpp, D. A. Tetrahedron Lett. 2011, 52, 2195. https://doi.org/10.1016/i.tetlet.2010.11.164

36. Raja, E. K.; DeSchepper, D. J.; Klumpp, D. A. Chem. Commun. 2012, 48, 814. https://doi.org/10.1039/c2cc34062c

37. Raja, E. K.; DeSchepper, D. J.; Nilsson Lill, S. O.; Klumpp, D. A. J. Org. Chem. 2012, 77, 5788. https://doi.org/10.1021/jo300922p

38. lakovenko, R. O.;Kazakova, A. N.; Muzalevskiy, V. M.; Ivanov, A. Y.; Boyarskaya, I. A.; Chicca, A.; Petrucci, V.; Gertsch, J.; Krasavin, M.; Starova, G. L.; Zolotarev, A. A.; Avdontceva, M. S.; Nenajdenko, V. G.; Vasilyev, A. V. Org. Biomol. Chem. 2015, 13, 8827.

https://doi.org/10.1039/C50B01072A

39. Prakash, G. K. S.; Narayanan, A.; Nirmalchandar, A.; Vaghoo, H.; Pakania, F.; Olah, G. A. J. Fluor. Chem. 2017, 196, 63.

https://doi.org/10.1016/i.jfluchem.2016.08.013

40. Prakash, G. K. S.; Pakania, F.; Vaghoo, H.; Rasul, G.; Mathew, T.; Olah, G. A. J. Org. Chem. 2010, 75, 2219. https://doi.org/10.1021/jo9026275 
41. Vaghoo, H.; Prakash, G. K. S.; Narayanan, A.; Choudhary, R.; Paknia, F.; Mathew, T.; Olah, G. A. Org. Lett. 2015, 17, 6170.

https://doi.org/10.1021/acs.orglett.5b03172

42. Safina, L. Y.; Selivanova, G. A.; Koltunov, K. Y.; Shteingarts, V. D. Tetrahedron Lett. 2009, $50,5245$. 